\title{
PUESTAS EN ESCENA DEL TEATRO CLÁSICO ESPAÑOL DEL SIGLO DE ORO Y DEL SIGLO XVIII EN JEREZ DE LA FRONTERA (1852-1900)
}

\author{
Francisco ÁLVAREZ HORTIGOSA \\ I.E.S. La Granja. Jerez de la Frontera. Cadiz \\ halvar@wanadoo.es
}

Resumen: Reconstrucción de la cartelera teatral de Jerez de la Frontera entre 1852 y 1900 , centrada en el teatro clásico español del Siglo de Oro y del siglo XVIII, atendiendo a las obras y autores representados, compañías y recepción crítica.

Abstract: Reconstruction of the theatre programming of Jerez de la Frontera between 1852 and 1900, centred on the Spanish classical theatre in the Golden Age and the XVIIIth Century, attending to the plays and the authors, companies and critical reception.

Palabras clave: Cartelera teatral. Historia del teatro representado. Teatro español áureo y del siglo XVIII. Jerez de la Frontera.

Key Words: Theatre programming. History of the theatre plays. Spanish theatre in the Golden Age and the XVIIIth Century. Jerez de la Frontera. 


\section{INTRODUCCIÓN}

Entre el 12 de abril de 1852 y el 7 de octubre de 1900, ambos inclusive, se anuncian en la prensa jerezana 2.057 obras, presentadas en 6.280 funciones por 312 compañías, en cuyos repertorios figuran hasta un total de 487 dramaturgos.

La nómina de locales teatrales de Jerez constaba del Teatro Principal, coliseo de tercer orden y único estable de la ciudad; los teatros Eguilaz-Echegaray y Eslava, con una presencia destacada desde mediados de la década de los setenta hasta mediada la década de 1880 y desde 1895 a 1900 , respectivamente; cuatro salones, ocho cafés cantantes, tres locales de carácter provisional y otros siete de aficionados, que ofrecieron funciones teatrales en distintos momentos de la segunda mitad del siglo XIX.

Los espectadores eran identificados desde crónicas o secciones de variedades en tres grupos que se correspondían con los tres niveles básicos de la sociedad jerezana: clases populares o bajas; clases medias; y el mundo elegante, clases altas. Sin apenas sentido crítico por su falta de preparación y cultura, muestran cierta preferencia por las obras musicales (Âlvarez Hortigosa, 2009).

En este contexto, el público jerezano tuvo la oportunidad de asistir a 27 funciones de 11 obras firmadas por 6 autores del Siglo de Oro español y a 24 representaciones de 5 obras de 2 autores pertenecientes al siglo XVIII, si bien uno de ellos, Leandro Fernández de Moratín, vive entre este último y el siglo XIX.

Abordamos el estudio del teatro español áureo y del siglo XVIII en la cartelera teatral jerezana, 1852-1900, con una relación de los dramaturgos y obras adscritos a ambos períodos, un análisis de las compañías que los pusieron en escena y la acogida que les dispensó la crítica. Reparamos en las veladas literarias o funciones conmemorativas celebradas en su honor y establecemos las conclusiones pertinentes ${ }^{1}$.

${ }^{1}$ Este trabajo sigue la metodología utilizada en el Centro de Investigación de Semiótica Literaria, Teatral y Nuevas Tecnologías (UNED), dirigido por el profesor José Romera Castillo, a quien agradezco sus indicaciones y sugerencias, cuyas actividades pueden verse en «Estudios sobre teatro» de la página electrónica http://www.uned.es/centro-investigacion-SELITEN@T/estudios_sobre_teatro.html. 


\section{LOS AUTORES Y SUS OBRAS. FECHA, LOCAL DE REPRESENTACIÓN Y COMPAÑÍAS TEATRALES}

Distinguimos en la siguiente relación, por orden alfabético, entre autores españoles del Siglo de Oro y del siglo XVIII. De cada autor apuntamos:

Junto a sus apellidos y nombre, en un primer paréntesis, cronología y lugar de nacimiento o fallecimiento del autor, en caso de tener constancia de ellos y, en un segundo paréntesis, las fechas que marcan el período de tiempo en que se representan sus obras, el número de ellas puestas en escena y el total de sus representaciones.

Sus obras, por orden alfabético, el género al que pertenecen; el día, hora y local en que tuvo lugar la representación, así como la compañía que la puso en escena.

\subsection{Autores españoles del Siglo de Oro}

CALDERÓN DE LA BARCA, Pedro (Madrid, 1600-1681) (1865-94 / 4 / 8).

A secreto agravio, secreta venganza (Drama, 3 actos y en verso).

16-V-1883, 20:30 h., Teatro Echegaray.

Compañía dramática dirigida por el primer actor D. Leopoldo Burón.

El Alcalde de Zalamea (Drama, 3 actos y en verso).

27-IX-1881, 20:00 h., Teatro Eguilaz.

Compañía dramática bajo la dirección del primer actor D. Antonio Vico.

16-II-1891, hora sin determinar, Teatro Principal.

Compañía dramática dirigida por el primer actor D. Antonio Vico.

Casa con dos puertas mala es de guardar (Comedia, 3 actos y en verso).

5-VII-1865, 20:30 h., Teatro Principal.

29-VII-1865, 20:30 h., Teatro Principal.

Ambas representaciones por la Compañía dramática dirigida por los primeros actores D. Victorino Tamayo y Baus y D. José Sánchez Albarrán. 
La vida es sueño (Drama, 3 jornadas y en verso).

3-X-1881, 20:00 h., Teatro Eguilaz.

Compañía dramática bajo la dirección del primer actor D. Antonio Vico.

30-XI-1894, 20:30 h., Teatro Principal.

25-XII-1894, 20:30 h., Teatro Principal.

Ambas representaciones por la Compañía cómico-dramática española, con el primer actor D. Francisco Fuentes.

CASTRO, Guillén de (Valencia, 1569-Madrid, 1631) (1858 / 1/1).

Las mocedades del Cid (Comedia en 3 actos).

20-VI-1858, 20:30 h., Teatro Principal.

Compañía dramática o de verso del Teatro Principal de Sevilla.

MORETO, Agustín (Madrid, 1618-Toledo, 1669) (1858-1900 / 2 / 4).

El desdén con el desdén (Comedia en tres jornadas).

19-XI-1897, hora sin determinar, Teatro Principal.

8-XII-1897, hora sin determinar, Teatro Principal.

Ambas representaciones por la Compañía cómico-dramática dirigida

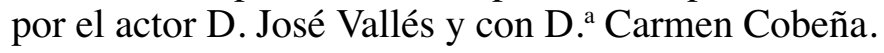

16-IX-1900, 20:30 h., Teatro Principal.

Compañía dramática española de D. ${ }^{a}$ María Guerrero y D. Fernando Díaz de Mendoza.

Las travesuras de Pantoja (Comedia en 3 actos).

5-II-1858, 19:00 h., Teatro de Santo Domingo.

Compañía dramática sin determinar.

ROJAS ZORRILLA, Francisco de (Toledo, 1607-Madrid, 1648) (1857$86 / 2 / 8)$.

Del rey abajo ninguno o García del Castañar (Comedia, 3 actos y en verso).

19-VII-1857, hora sin determinar, Teatro Principal. 
Compañía de verso dirigida por el primer actor D. Pedro Rodés, junto a una Compañía de Zarzuela.

20-IV-1862, 20:00 h., Teatro Principal.

Compañía de declamación y baile con el primer actor D. Francisco de Paula Gómez.

26-V-1863, 20:30 h., Teatro Principal.

Compañía dramático-coreográfica dirigida por el primer actor D. Francisco de Paula Gómez.

13-IV-1873, 20:00 h., Teatro Principal.

Compañía dramática dirigida por el primer actor D. Enrique F. y Jáuregui.

29-X-1882, 20:00 h., Teatro Eguilaz.

Compañía dramática dirigida por los primeros actores D. Pedro Delgado y D. Alfredo Maza.

4-VI-1884, 20:30 h., Teatro Echegaray.

Compañía de declamación dirigida por el primer actor D. Victorino Tamayo y Baus.

10-XII-1886, 19:30 h., Teatro Echegaray.

Compañía dramática dirigida por el primer actor D. Alfredo Maza.

Lo que son mujeres (Comedia, 3 jornadas y en verso).

14-XI-1852, hora sin determinar, Teatro Principal.

Compañía cómico-lírica sin determinar.

TÉLLEZ, Gabriel (Tirso de Molina) (Falleció en Soria en 1648) (1852$1900 / 2 / 3)$.

El castigo del penseque (Comedia, 3 actos).

1-II-1900, 20:30 h., Teatro Principal.

Compañía cómico-dramática de D. ${ }^{a}$ Carmen Cobeña.

El vergonzoso en palacio (Comedia, 3 actos).

26-XI-1897, hora sin determinar, Teatro Principal. 
Compañía cómico-dramática dirigida por el primer actor D. José Valles y con D. ${ }^{a}$ Carmen Cobeña.

13-II-1900, 20:30 h., Teatro Principal.

Compañía cómico-dramática de D. ${ }^{a}$ Carmen Cobeña.

VEGA Y CARPIO, Félix Lope de (Madrid, 1562-1635) (1870-1900 / 1 / 3).

La niña boba (Adaptación de La dama boba, Comedia, 3 actos).

3-VII-1870, 20:30 h., Teatro Principal.

Compañía dramática dirigida por D. Victorino Tamayo y Baus.

28-II-1878, 20:00 h., Teatro Principal. Baus.

Compañía dramática dirigida por el primer actor D. Victorino Tamayo y

5-II-1900, 20:30 h., Teatro Principal.

Compañía cómico-dramática de Carmen Cobeña.

\subsection{Autores españoles del siglo XVIII}

CRUZ, Ramón de la (Madrid, 1731-1794) (1860-94 / 3 / 22).

La comedia de las maravillas o Los payos en el ensayo (Sainete).

2-VIII-1863, 20:30 h., Teatro Principal.

14-VIII-1863, 20:30 h., Teatro Principal.

Ambas representaciones por la Compañía dramática y coreográfica dirigida por el bailarín D. Ambrosio Martínez.

10-VI-1866, 21:00 h., Teatro Principal.

Compañía dramática dirigida por el primer actor D. José María de Vivancos.

1-VIII-1875, 20:15 h., Teatro Eguilaz.

Compañía cómica dirigida por el primer actor D. José Sánchez Albarrán.

El payo de la carta (Sainete). 
22-IV-1860, 16:00 h., Teatro Principal.

Compañía dramática dirigida por el primer actor D. José Lozano.

12-X-1860, 19:30 h., Teatro Principal.

Compañía de verso, con una sección lírica, dirigida por el primer actor D. Rafael Farro.

24-VI-1862, 20:30 h., Teatro Principal.

Compañía de declamación y baile con el primer actor D. Francisco de Paula Gómez.

25-V-1865, 20:00 h., Teatro Principal.

Compañía dramática dirigida por D. Victorino Tamayo y D. José Sánchez Albarrán.

26-IV-1866, 20:00 h., Teatro Principal.

Compañía dramática dirigida por el primer actor D. José María de Vivancos.

3-II-1867, 19:30 h., Teatro Principal.

Compañía dramática dirigida por los primeros actores D. Francisco Galván y D. José Corte.

9-X-1867, 16:30 h., Café Cantante del Conde.

Compañía de zarzuela con la primera tiple D. ${ }^{a}$ Antonia García de Videgain.

26-VII-1868, 17:00 h., Café Cantante del Conde.

Compañía de zarzuela con el primer tenor D. Martín Goenaga.

31-I-1869, 16:30 h., Café Cantante del Conde.

4-II-1869, 19:30 h., Café Cantante del Conde.

Ambas representaciones por una Compañía dramática sin determinar.

26-X-1882, 20:00 h., Teatro Eguilaz.

Compañía dramática dirigida por los primeros actores D. Pedro Delgado y D. Alfredo Maza.

6-VIII-1884, 20:30 h., Café Cantante del Principal.

16-VIII-1884, 20:30 h., Café Cantante del Principal. 
Ambas representaciones por una Compañía dramática sin determinar.

20-V-1894, 20:30 h., Teatro Principal.

Compañía cómico-dramática Treviño con el primer actor D. Francisco Fuentes.

21-XI-1894, 20:30 h., Teatro Principal.

Compañía cómico-dramática española con el primer actor D. Francisco Fuentes.

El viudo (Sainete).

7-V-1876, 20:00 h., Teatro Eguilaz.

21-V-1876, 20:30 h., Teatro Eguilaz.

Ambas representaciones por la Compañía dramática del primer actor D. Pedro Delgado.

29-IV-1883, 20:30 h., Teatro Echegaray.

Compañía dramática dirigida por el primer actor D. Leopoldo Burón.

FERNÁNDEZ DE MORATÍN, Leandro (Madrid, 1760-1828) (1870$85 / 2 / 2$ ).

La comedia nueva o El café (Comedia, 2 actos y en prosa).

16-VII-1870, 20:30 h., Teatro Principal.

Compañía dramática dirigida por el primer actor D. Victorino Tamayo y Baus.

La escuela de los maridos (Comedia, 3 actos).

21-V-1884, 20:30 h., Teatro Echegaray.

Compañía de declamación dirigida por el primer actor D. Victorino Tamayo y Baus.

\section{LAS COMPAÑÍAS}

En Jerez se presentan 312 compañías durante la segunda mitad del siglo XIX. Aunque actúan casi el mismo número de compañías de teatro lírico, 152 , que de teatro declamado, 160, las representaciones de las primeras suman 4.427 (70,5\%) y las segundas sólo llegan a las 1.853 (29,5\%). Estas ci- 
fras confirman la preferencia de los jerezanos por el género musical. Las representaciones dramáticas, en combinación con las cómicas, se mantienen constantes a lo largo de este período, con una mayor incidencia desde principios de los años sesenta hasta los primeros años ochenta.

El 92\% de las funciones dramáticas tienen lugar en los teatros Principal y Eguilaz-Echegaray, con un predominio claro del primero que acapara el $71 \%$. En general, las grandes compañías, que requieren un escenario mejor acondicionado para sus representaciones, trabajan en dichos coliseos. Los locales pequeños reciben a compañías de menor categoría, que suelen ejecutar funciones más ligeras.

La estancia de las compañías dramáticas en la ciudad se acorta con respecto a las de zarzuela, debido a la predilección del público jerezano por este género y a las menores exigencias para su puesta en escena.

Las compañías que ponen obras del Siglo de Oro ascienden a 21: 8 representan a Rojas Zorrilla; 6 a Calderón; 2 a Moreto; 2 a Lope; 1 a Guillén de Castro; 1 a Moreto y Tirso; y 1 a Tirso y Lope. Dieciocho compañías incluyen en su repertorio obras de autores del siglo XVIII: 16 de Ramón de la Cruz y 2 de Leandro Fernández de Moratín. Además, de las 21 compañías que presentan autores del Siglo de Oro, 5 pusieron a su vez obras de Ramón de la Cruz y 2 de Moratín. Por tanto, el total de compañías que se acercaron a los autores del Siglo de Oro y del siglo XVIII fue de 31.

El Teatro Principal acogió 15 compañías que representaron a los clásicos y 10 a autores del siglo XVIII. El Teatro Eguilaz-Echegaray, 5 compañías de cada período. Una Compañía interpretó a Agustín Moreto en el Teatro de Santo Domingo y otras tres los sainetes de Ramón de la Cruz en el Café Cantante del Conde.

Por décadas, en los años noventa 6 compañías ofrecen obras clásicas en Jerez, 5 en los ochenta, 4 en los cincuenta y sesenta y sólo 2 en los setenta. Las compañías que montaron obras del siglo XVIII, destacan, en los años sesenta, 10, mientras 3 lo hicieron en los ochenta, 2 en los setenta y noventa y 1 en los cincuenta. De las temporadas, registran un mayor número de estas compañías la de 82-83, cuatro, y la de 94-95, tres. En 26 temporadas, de un total de 49, al menos una compañía llevó al escenario a algún autor del Siglo de Oro o del siglo XVIII.

Entre los tipos de compañías que representan obras clásicas sobresalen 13 dramáticas. A dos de estas se les aplica también el apelativo de verso, a una de declamación y a otra española. Les siguen 4 cómico-dramáticas, 2 cómico-líricas y 2 dramático-coreográficas o de declamación y baile. Los autores 
del siglo XVIII son representados por 11 compañías dramáticas, 2 dramáticocoreográficas o de declamación y baile, 2 cómico-dramáticas, 1 de verso con sección lírica, 1 de zarzuela y 1 cómica. De 6 compañías, 2 que presentan obras del Siglo de Oro y 4 que ponen en escena autores del siglo XVIII, sólo conocemos los nombres de algunos de sus miembros y el tipo de obras que componen su repertorio.

El número de actores que integran las compañías dramáticas oscila entre los 27 que trabajan en la de Tamayo-Albarrán y Delgado-Maza, los 20 de las dirigidas por Vivancos y Galván, los 21 de la de Tamayo, 19 la de Vallés-Cobeña, 18 las de Lozano y Farro, y 15 la de Francisco de Paula Gómez. Las compañías de Tamayo-Albarrán y Francisco de Paula Gómez se completan con sendas secciones coreográficas de 10 y 12 bailarines, respectivamente, mientras que la compañía dirigida por Rafael Farro presenta el aliciente de una sección lírica de 5 miembros, cuatro de los cuales ejercen a su vez como actores o actrices. El personal encargado de maquinaria, pintura, peluquería o sastrería, pertenece con frecuencia a la nómina del local donde actúan las compañías.

Por las obras clásicas que ofrecen, la importancia de sus principales actores y la buena acogida que reciben por parte de la prensa decimonónica jerezana, prestamos especial atención a compañías como las de Victorino Tamayo y Baus, Carmen Cobeña, Antonio Vico, Rafael Farro, Francisco de Paula Gómez y María Guerrero.

Tamayo representa en dos ocasiones Casa con dos puertas mala es de guardar, de Calderón, en la temporada 64-65, como director de una compañía que contaba también con uno de los actores más populares en Jerez, José Sánchez Albarrán. Con La niña boba, de Lope (adaptación de La dama boba), llega al Principal en julio de 1870 y febrero de 1878, y protagoniza Del rey abajo ninguno en junio de 1884 en el Eguilaz-Echegaray. Precisamente la Compañía de Tamayo es también la única que monta en la escena jerezana dos obras de Leandro Fernández de Moratín durante la segunda mitad del siglo XIX, La comedia nueva o El café y La escuela de los maridos. Se dice de Tamayo que es, entre todos los grandes actores, «el que más simpatías ha demostrado siempre por Jerez» (El Guadalete, 10-2-1878, n. ${ }^{\circ}$ 6.607, Gacetillas). Desde El Guadalete se considera, en 1865, que su compañía es de las más notables que pueden combinarse en España (El Guadalete, 15-8-1865, n. ${ }^{\circ} 3.952$, Crónica Local) y, en 1870, El Progreso sostiene que no es posible que la compañía reunida por Tamayo encuentre rival en ningún otro teatro de los de primer orden del país (El Progreso, 23-6-1870, 
n. ${ }^{\circ} 385$, Sección Local) y para que los lectores no dudemos de tal aseveración se escriben crónicas como la siguiente:

Pero lo que no debemos dejar de consignar, es el afán creciente y progresivo que muestra el público por los actores que forman esta brillante compañía: afán de manifiesta adhesión, o entusiasmo frenético por sus triunfos. Allí no se pierde un rasgo, una mirada, un detalle: se escuchan con religioso silencio.

La Srta. D. ${ }^{a}$ Elisa Boldun sigue haciendo las delicias de nuestro público, impresionado cada vez más en su favor, cada vez más entusiasta de sus bellas gracias [...], de naturalidad tan espontánea, que parece que el arte y su mismo corazón se hallan misteriosamente identificados. Le hace sentir con tan ingenua emoción, que no concibe un más allá en la expresión de los sentimientos dramáticos humanos. Joya del teatro es nuestra Elisa Boldun, que cautiva con su talento, atrae con su hermosura, persuade con su palabra y acaricia con su donaire las primaverales fantasías del alma.

El otro genio de la escena, el Sr. Tamayo, nos lleva a lo intimo de nuestro ser, bajo una superficie simpática, un fondo altamente filosófico: su palabra no es ya el susurro, el aura como la de aquella, sino el oráculo; ambos personifican la verdadera magia de Talía, ambos la inspiración, ambos el arte [...] (El Progreso, 23-6-1870, n. ${ }^{\circ}$ 385, Sección Local).

La compañía de la Cobeña recala en Jerez en los últimos años del siglo. En 1897 pone en escena El desdén con el desdén y El vergonzoso en palacio, obra que repite en sus actuaciones en el Teatro Principal, en 1900, junto a $L a$ niña boba y El castigo del penseque. Esta gran actriz es para los cronistas jerezanos la sucesora de Elisa Mendoza Tenorio, poseedora de las dos cualidades privativas de la Tubau y la Guerrero:

[...] intención y tensión, un tanto atenuadas por la dulzura de expresión...; los destellos de su mirada y los latidos de su corazón se exteriorizan en un tono pasional siempre tierno y delicado, que subyuga a los espectadores... Carmen es bella en el rostro y esbelta y airosa en el cuerpo [...]

Discípula aprovechadísima de Mario, de él conserva la verdad en el decir y el arte de subrayar, como de Vico aprendiera el fugaz destello trágico y el centelleo pasional deslumbrante [...]

Es, pues, la dama de las damas [...] (El Guadalete, 27-11-1897, n. ${ }^{\circ} 12.839$, Carmen Cobeña).

Antonio Vico protagoniza, en 1881, dos de los grandes títulos de Calderón de la Barca, La vida es sueño y El Alcalde de Zalamea, obra que vuelve a presentar diez años después en su ciudad natal. 
Acerca de la compañía, dirigida por el primer actor Rafael Farro, en la temporada 1860-61, se reconoce que será de verso con una sección lírica para ejecutar ciertas zarzuelas que no exijan un personal muy numeroso, sin más pretensión que procurar al público un solaz ameno e instructivo en las dilatadas noches de invierno (El Guadalete, 4-10-1860, n. ${ }^{\circ} 2.451$, Crónica Local). De Farro se comenta que es un buen actor:

[...] procedente de la corte. Pertenece a esa nueva escuela que cultiva con predilección la comedia del mundo elegante, o el drama con frac. Dice bien, tiene naturalidad, buenas maneras, rostro expresivo, y no poca intención y talento cómico.

Los demás actores figuran en segundo término, y en justicia no descomponen los más de ellos el cuadro (Revista del Guadalete, 15-10-1860, n. ${ }^{\circ}$ XLII).

La compañía de Francisco de Paula Gómez repite dos temporadas seguidas, 61-62 y 62-63, su representación de la obra de Rojas Zorrilla Del rey abajo ninguno y, al igual que en la compañía anterior, se hace hincapié en el poderoso aliciente que supone, en este caso, contar con una sección coreográfica (Revista del Guadalete, 7-7-1862, n. ${ }^{\circ}$ XXVII, TEATRO).

María Guerrero y Fernando Díaz de Mendoza son aclamados desde la prensa jerezana, ante todo, por sus interpretaciones de los considerados grandes autores del siglo XIX, como Tamayo o Echegaray, pero también protagonizan con gran éxito la obra de Agustín Moreto El desdén con el desdén.

Otras compañías, dirigidas por Pedro Rodés, en la temporada 56-57, cuentan con una sección de zarzuela «bastante buena» y otra de verso «que satisface las exigencias de nuestro teatro» (El Guadalete, 13-12-1856. n. ${ }^{\circ}$ 1.180, REVISTA TEATRAL); José Lozano, que centra la cartelera jerezana en los meses de abril y mayo de 1860 , de cuya compañía se apunta que difícilmente podrá reunirse una «tan bien dotada» (El Guadalete, 14-4-1860, n. ${ }^{\circ}$ 2.303, Crónica Local); Francisco Galván, que llega precedido de una buena acogida en Cádiz (El Guadalete, 15-1-1867, n. ${ }^{\circ}$ 4.383, Crónica Local); Francisco Fuentes, que interpretó La vida es sueño en 1894; Leopoldo Burón o Pedro Delgado, completan la relación de las que mostraron al público jerezano las obras de nuestros clásicos.

La puesta en escena de los sainetes de Ramón de la Cruz corre a cargo de compañías dramáticas de primer orden, que los incluyen en su repertorio para aligerar y hacer más variadas las funciones, y de otras de segundo nivel que incluso suben a este autor a los pequeños escenarios de los cafés cantantes del Principal y del Conde. 
Apuntemos, para completar este apartado dedicado a las compañías, las noticias aparecidas en la prensa jerezana relativas a quienes las formaban, las fechas que permanecieron en la ciudad y el número de funciones ejecutadas.

Compañía dramática o de verso dirigida por el primer actor D. José Lozano.

Teatro Principal. Temporada 1859-60.

Representa El payo de la carta, de Ramón de la Cruz, el día 22-04-1860.

- Lista de la compañía.

- Representante de la empresa, D. Eduardo Calmerino.

- Primer actor de carácter y director de escena, D. José Lozano.

- Primeros actores, D. Elías Aguirre y D. Florencio Quintana.

- Galán joven, D. Francisco Jiménez.

- Carácter anciano, D. Manuel Monsalve y D. León Carvajal.

- Primer actor cómico, D. José Quer.

- D. Vicente Savedra, D. N. N., D. Manuel Más.

- Primera actriz, D. ${ }^{a}$ Antonia Scapa.

- Otra primera y dama joven, D. ${ }^{a}$ Lutgarda García.

- Matrona y característica, D. ${ }^{a}$ Concepción Rodríguez.

- Actrices del género cómico, D. ${ }^{a}$ Lutgarda García, D. ${ }^{a}$ Josefa Jurado.

- D. ${ }^{a}$ Dolores Rodríguez, D. ${ }^{a}$ Ana Savedra, D. ${ }^{a}$ Agustina García.

- Apuntadores, primero, D. Manuel Guerrero. Segundo, D. José Scapa.

La mayoría de los primeros actores, son los que han actuado en la temporada pasada en el Teatro de San Fernando de Sevilla.

(El Guadalete, 31-3-1860, n. ${ }^{\circ}$ 2.292).

- Entre el 8-4-60 y el 27-5-60: 31 funciones. 
Compañía de verso, con una sección lírica, dirigida por el primer actor D. Rafael Farro.

Teatro Principal. Temporada 1860-61.

Representa El payo de la carta, de Ramón de la Cruz, el día 12-10-1860.

- Lista de la compañía.

- Representante de la Empresa, D. Gabriel Sánchez de Castilla.

- Director de escena, D. Rafael Farro.

- Primer actor, D. Rafael Farro.

- Segundo ídem, D. Francisco Galbán.

- Galán joven, D. Juan Manuel Arroyo.

- Primer actor cómico y Director en su género, D. José Sapera.

- Primer actor de carácter anciano, D. Mariano Ballesteros.

- Segundo ídem, D. Francisco Pastor.

- Para galanes jóvenes, D. Dámaso Scapa.

- Actores, D. Antonio Luzuriaga y D. Gabriel Sánchez.

- Primera actriz, D. ${ }^{a}$ Antonia Scapa.

- Segunda ídem, D. ${ }^{a}$ María Jauregui.

- Dama joven, D. ${ }^{a}$ Vicenta Cruz.

- Dama matrona y característica, D. . María Cruz.

- Primera actriz cómica, D. ${ }^{\mathrm{a}}$ Luisa Morilla.

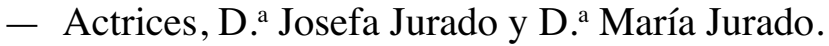

- Consuetas, D. Francisco Muñoz y D. Antonio Robles.

Sección Lírica: Maestro Director, D. Manuel Rodríguez. D. José Sapera. D. Antonio Luzuriaga. D. ${ }^{a}$ María Jauregui. D. . Vicenta Cruz.

- Director de orquesta, D. Francisco Ramírez.

- Pintor, D. Gabriel Sánchez y Quesada.

- Maquinista, D. Francisco Gil.

- Guardarropa, D. Luis Sánchez y Jiménez.

- Encargado del vestuario, D. Antonio Aguilar.

(El Guadalete, 4-10-1860, n. ${ }^{\circ}$ 2.451, Crónica Local).

- Entre el 6-10-60 y 14-2-61: 65 funciones. 
Compañía de declamación y baile, con el primer actor D. Francisco de Paula Gómez.

Teatro Principal. Temporada 1861-62.

Representa Del rey abajo ninguno, de Rojas Zorrilla, el día 20-04-1862 y El payo de la carta, de Ramón de la Cruz, el día 24-06-1862.

- La Empresa que ha tomado el teatro, ha formado dos compañías, de declamación y de baile.

- Lista de la compañía.

- Actrices: Primera actriz, D. ${ }^{a}$ Lorenza Fina Segarra. Primera actriz cómica y primera dama joven, D. ${ }^{a}$ Antonia Segura. Característica, D. ${ }^{a}$ Flora Muñoz. Graciosa, D. ${ }^{a}$ Clara Navarro. Dama joven, D. ${ }^{a}$ Eloísa Rico. Otra íd., D. a Ángela Díaz.

- Actores: Primer actor, D. Francisco de Paula Gómez. Segundo actor, D. Sebastián Becchio. Galán joven, D. José Navarro. Primer actor de carácter, D. José Lago. Primer actor cómico, D. José María Gómez. D. Gabriel S. Castilla. D. Gabriel Muñoz. D. Ricardo López. D. Luis García. cía.

- Primer apuntador, D. Juan Natera. Segundo apuntador, D. Luis Gar-

- Cuerpo coreográfico.

- Primer bailarín y director, D. Ambrosio Martínez. Primera bailarina, D. ${ }^{a}$ Luisa Medina. D. ${ }^{a}$ Dolores Olivier, D. ${ }^{a}$ Reyes Olivier, D. ${ }^{a}$ Rosario Martínez, D. ${ }^{a}$ Carolina Fernández, D. ${ }^{a}$ María Pleiteado, D. ${ }^{a}$ Ana Olier, D. José Martínez, D. Guillén Romero, D. Juan Sánchez, D. José Jaime.

- Representante de la Empresa, D. José Moreno Navarro. Director de la sastrería, D. José Farro. Maquinista, D. Francisco Gil. Guardarropa, D. N. Sánchez.

(El Guadalete, 16-4-1862 , n. ${ }^{\circ}$ 2.927, Crónica Local).

- Entre el 20-4-62 y el 17-8-62: 51 funciones. 
Compañía dramática dirigida por los primeros actores D. Victorino Tamayo y Baus y D. José Sánchez Albarrán.

Teatro Principal. Temporada 1864-65.

Pone en escena El payo de la carta, de Ramón de la Cruz, el día 25-051865 y Casa con dos puertas mala es de guardar, de Calderón, los días 5 y 29-07-1865.

- Compañía dramática procedente de los teatros Principal de Cádiz y Principal de Granada, dirigida por los primeros actores y directores D. Victorino Tamayo y Baus y D. José Sánchez Albarrán.

- Lista de la compañía.

- Actores.

- Primeros y directores de escena, D. Victorino Tamayo y Baus y D. José Sánchez y Albarran.

- Segundo y suple a los primeros, D. Francisco Galbán.

- Primer galán joven, D. Manuel Palau.

- Primer actor de carácter, D. Mariano Ballesteros.

- Actor cómico, D. Domingo Ruiz.

- Galanes jóvenes, D. Manuel Vicó y D. Rafael Valladares.

- Segundo actor cómico, D. Federico Guerrero. D. José Marín. D. José Martínez. D. Bernardo Martínez. D. Rafael García. D. José Guerrero.

- Actrices.

- Primera actriz y dama joven, D. ${ }^{\mathrm{a}}$ Julia Santigosa.

- Dama matrona, D. ${ }^{a}$ Adelaida Toral.

- Primera característica, D. ${ }^{a}$ Catalina Mirambell.

- Primera dama joven y actriz cómica, D. ${ }^{\mathrm{a}}$ Carolina Santos.

- Damas jóvenes, D. ${ }^{\mathrm{a}}$ Ángela Quintana y D. ${ }^{\mathrm{a}}$ Josefa Martínez. D. ${ }^{a}$ Victoria Valladares. D. ${ }^{a}$ Eloísa Martínez. D. ${ }^{a}$ Dolores Ballesteros. D. ${ }^{a}$ Josefa Lara. Cabello.

- Niñas, Srta. Josefa Santigosa. Srta. Emilia Ballesteros. Srta. Victoria

- Agente de la empresa, D. José Moreno de la Torre. 
- Apuntadores, D. Juan Natera. D. José Marín. D. José Santos.

- Cuerpo coreográfico.

- Primer bailarín y director, D. Salvador Mateu.

- Primera bailarina, D. a Antonia Cabello.

- D. Antonio Fernández, D. Francisco Perlá, D. Federico Guerrero, D. José de la Oliva, D. ${ }^{a}$ María Pleiteao, D. ${ }^{a}$ Carolina Fernández, D. ${ }^{a}$ María Espinosa, D. ${ }^{a}$ Dolores Sabio.

- Maestro director de orquesta, D. Francisco Ramírez.

- Cobrador principal, D. Feliciano Martín.

- Maquinista, D. Francisco Gil.

- Guardarropa, D. Luis Sánchez.

- Sastre, D. N. N.

- Peluquero, D. N. N.

(El Guadalete, 16-4-1865, n. ${ }^{\circ} 3.848$, Crónica Local).

- Entre el 16-4-65 y el 15-8-65: 60 funciones.

Compañía dramática, con primer actor y director de escena, D. José María de Vivancos.

Teatro Principal. Temporada 1865-66.

Pone en escena El payo de la carta, de Ramón de la Cruz, el día 26-041866.

- Lista de la compañía.

- Representante de la empresa, D. José Moreno de la Torre.

- Primer actor y director de escena, D. José María de Vivancos.

- Otros primeros actores y directores en sus funciones, D. Jacinto Aranaz, D. José Corte.

- Primer actor y director del género cómico, D. José Navarro.

- Actores.

- Primer actor, D. José María de Vivancos.

- Segundo íd., D. Jacinto Aranaz. 
- Actor de carácter, D. José Corte.

- Primer actor cómico, D. José Navarro.

- Galán joven, D. Carlos Espinosa.

- Primer gracioso, D. Ramón Carrillo.

- Segundo barba, D. José Garrido.

- Subalternos, D. José Espinosa, D. Juan González, D. José Ponce.

- Actrices.

- Primera actriz, D. ${ }^{a}$ Francisca Carbonell.

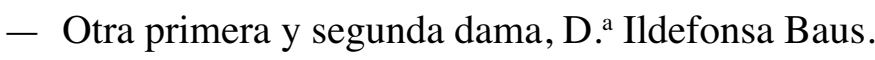

- Dama joven, D. ${ }^{\text {a Amalia Mela. }}$

- Característica, D. Josefa Cruz.

- Actriz cómica, D. ${ }^{a}$ Amparo Nieto.

- Subalternas, D. ${ }^{a}$ Ascensión Teruel, D. ${ }^{a}$ Matilde Vivancos, D. ${ }^{a}$ Adelaida Bagaz, D. ${ }^{a}$ Encarnación Iriarte.

- Apuntadores, D. Antonio Péndola, D. José Ponce.

- Director de orquesta, D. Francisco Ramírez.

- Encargado del vestuario, D. Antonio Luna.

- Maquinista, D. Francisco Gil.

- Adornista, D. Luis Sánchez.

(El Guadalete, 24-5-1866, n. . 4.192, Crónica Local).

- Entre el 1-4-66 y el 26-7-66: 48 funciones.

Compañía dramática, con primeros actores y directores, D. Francisco Galván y D. José Corte.

Teatro Principal. Temporada 1866-67.

Pone en escena El payo de la carta, el día 3-02-1867.

- Cuadro de artistas que actúan en el Teatro Principal de Cádiz.

- Lista de la compañía.

- Representante de la Empresa, D. Antonio Bono. 
- Primeros actores y directores de escena, D. Francisco Galván, D. José Corte.

- Primera actriz, D. ${ }^{a}$ Matilde Martínez de Aznar.

- Primer actor y director, D. Francisco Galván.

- Segundo actor y suple al primero, D. Sebastián Vechio.

- Primer actor de carácter y director en su género, D. José Corte.

- Primeros galanes jóvenes, D. Enrique Martínez, D. Antonio Jiménez.

- Primeros actores y directores del género cómico, D. Antonio Muñoz, D. Domingo Ruiz.

- Barba, D. Salustiano Muñoz.

- Subalternos, D. José Esteve, D. Pablo Morilla.

- Primera actriz, D. ${ }^{a}$ Matilde Martínez de Aznar.

- Otra primera actriz y dama joven, D. ${ }^{a}$ Eloísa Rico de Rossi.

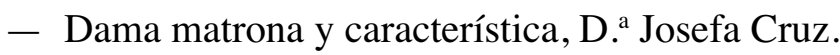

- Primera dama joven, D. ${ }^{\mathrm{a}}$ Josefa Rizzoli.

- Actrices cómicas, D. ${ }^{a}$ Manuela Fernández, D. ${ }^{a}$ Vicenta Perlá.

- Segunda dama joven, Srta. D. ${ }^{a}$ Carmen Lerate.

- Subalterna, D. ${ }^{a}$ Pelegrina Sánchez.

- Consueta, D. Rafael Garcés.

- Director de orquesta, D. Francisco Ramírez.

- Cobrador principal, D. Feliciano Martín.

- Maquinista, D. Francisco Gil.

- Sastre, D. Antonio Luna.

- Guardarropa, D. Luis Sánchez.

(El Guadalete, 18-1-1867, n. ${ }^{\circ} 4.387$, Crónica Local).

- Entre el 19-1-67 y el 24-3-67: 15 funciones. 

Baus.

Compañía dramática dirigida por el primer actor D. Victorino Tamayo y

Teatro Principal. Temporada 1869-70.

Representa La niña boba, de Lope de Vega, el día 3-07-1870, y La comedia nueva o El café, de Moratín, el día 16-07-1870.

- Lista de los actores de la compañía.

- Primer actor y director de escena, D. Victorino Tamayo.

- Primeras actrices, D. ${ }^{a}$ Elisa Boldún y D. ${ }^{a}$ Silveria del Castillo.

- Primer actor y director del género cómico, D. Mariano Fernández.

- Otro primer actor, D. Juan Casaner.

- Actores: D. Juan Mela, D. Manuel Cancela, D. Domingo Mendoza, D. Julio L. Perié, D. Pedro Imperial, D. Salustiano Muñoz, D. Adolfo Belo, D. Juan Casanova, D. Luis Blanco.

- Actrices: D. ${ }^{a}$ Clotilde Lambía, D. ${ }^{a}$ María Imperial, D. ${ }^{a}$ Amalia Vandenver, D. ${ }^{a}$ Enriqueta Imperial, D. ${ }^{a}$ Amalia Safra, D. ${ }^{a}$ Eloísa Durán, D. ${ }^{a}$ Esperanza Durán.

- Apuntadores, D. Enrique Garín y D. Antonio Flores.

- Representante de la Empresa, D. José María Rosado.

(El Progreso, 25-5-1870, n. . 362, Sección Local).

- Entre el 30-5-70 y 22-8-70: 38 funciones. gui.

Compañía dramática dirigida por el primer actor D. Enrique F. y Jáure-

Teatro Principal. Temporada 1872-73.

Pone en escena Del rey abajo ninguno, de Rojas Zorrilla, el día 13-041873.

- Lista de la compañía.

- Primer actor y director de escena, D. Enrique F. y Jáuregui.

- Primera actriz, doña Carolina Gilly.

- Primer actor y director del género cómico, D. Eduardo García.

- Otra primera actriz y primera dama joven, doña Carolina Santos. 
- Dama matrona y característica, doña Cornelia Pellizzari.

- Actriz cómica, doña Fermina Vilches.

- Dama joven, doña Cándida Pardo. Actrices, doña Francisca Montero, doña Pilar Maldonado y doña Carmen Fernández.

- Para papeles especiales, Srta. Concepción Montero.

- Primer actor de carácter, D. Francisco Peluzzo.

- Segundo galán, D. Miguel Marcén.

- Galanes jóvenes, uno en ajuste (la empresa anuncia que está próxima a terminar su contrato con el galán joven del Teatro Español, D. Enrique Sánchez) y D. Manuel Cancela.

- Otro barba y característico, don Joaquín Alcalde.

- Segundo gracioso, D. Adolfo Gil.

- Segundo galán joven, D. Guillermo Pardo.

- Actores, D. Antonio Vilches, don Mariano Velasco y D. Francisco Gil.

- Apuntadores, D. Federico Senés y D. Baldomero Vilches.

- Cobrador principal, D. José Salas.

- Director de orquesta, D. Francisco Ramírez.

- Sastre, D. Antonio Luna.

(El Guadalete, 9-4-1873, n. ${ }^{\circ}$ 5.114).

- Entre el 13-4-73 y el 16-4-73: 3 funciones.

Compañía dramática española, dirigida por los primeros actores D. Pedro Delgado y D. Alfredo Maza.

Teatro Eguilaz. Temporada 1882-83.

Pone en escena El payo de la carta, de Ramón de la Cruz, el día 26-101882, y Del rey abajo ninguno, de Rojas Zorrilla, el día 29-10-1882.

- Lista del personal artístico.

- Primeros actores y directores, D. Pedro Delgado y D. Alfredo Maza.

- Primer actor, D. Emilio Villegas. 
- Primer actor cómico, D. Tomás Infante.

- Primer actor, D. Francisco Gómez.

- Primeras actrices, D. ${ }^{a}$ Elvira González, D. ${ }^{a}$ Elisa Rosas.

- Actrices: D. ${ }^{a}$ Elvira Alverá, D. ${ }^{a}$ Adela Coronado, D. ${ }^{a}$ Elvira González, D. ${ }^{a}$ Josefina Montes, D. ${ }^{a}$ Petra Martínez, D. ${ }^{a}$ Elisa Rosas, D. ${ }^{a}$ Enriqueta Val, D. a Josefa Val, D. . Luisa Zoriano, D. ${ }^{a}$ María Zúñiga.

- Actores: D. Alfonso Carmelo, D. Pedro Delgado, D. Antonio Galé, D. Francisco Gómez, D. Joaquín Huarte, D. Tomás Infantes, D. Alfonso Leonardo, D. Alfredo Maza, D. Manuel Sabater, D. Tomás Torre, D. Emilio Villegas, D. Francisco Zoriano.

- Cuatro racionistas de ambos sexos.

- Apuntadores, D. José Ramírez, D. Eugenio Cabello.

(El Guadalete, 19-10-1882, n. . 8.150, Gacetillas).

- Entre el 19-10-82 y el 12-11-82: 13 funciones.

Compañía cómico-dramática dirigida por el actor D. José Vallés y de la que forma parte la eminente actriz señorita Carmen Cobeña.

Teatro Principal. Temporada 1897-98.

Representa El desdén con el desdén, de Moreto, los días 19-11 y 8-121897, y El vergonzoso en palacio, de Tirso de Molina, el día 26-11-1897.

- Lista de la compañía.

- Actrices: Arévalo, Antonia; Cobeña, Carmen; García, Josefa; Parejo, Eloísa; Peña, Herminia; Rodríguez, María; Sampedro, Mercedes; Tovar, Rosa; Valentín, María y Vedía, Trinidad.

- Actores: Cuevas, Agapito; Cerro, Julio del; Chaves, Pablo; Domínguez, Manuel; Guerrero, Francisco; Moreno, Pedro; Ruiz, Leovigildo; Vallés, José; Valentín, Leopoldo y Vigo, Manuel.

(El Guadalete, 11-11-1897, n. ${ }^{\circ} 12.823$, Gacetillas).

- Entre el 17-11-97 y el 9-12-97: 23 funciones.

Basándonos en los datos hasta aquí expuestos, podemos concluir que las compañías que representaron a los clásicos en Jerez eran dramáticas, de verso o declamación, dirigidas en bastantes ocasiones por eminentes actores 
de la escena teatral española, que incluyen en sus funciones, compuestas básicamente por autores del siglo XIX, algunas de las grandes obras del Siglo de Oro. Cinco de ellas cuentan con secciones coreográficas o líricas para hacer más atractivo su repertorio, ya que el público exige variedad en los espectáculos teatrales y más en una ciudad como Jerez donde el respetable no debía renovarse con facilidad.

\section{RECEPCIÓN CRÍTICA}

La mayor parte de la información que hemos recabado sobre teatro en la prensa jerezana procede de gacetillas breves, concisas y sin firma. Las secciones dedicadas al teatro, Variedades, Crónicas, etc. tampoco suelen ser amplias y también aparecen en muchos casos sin firmar. Las limitaciones de espacio, el hecho de que escribir en la prensa sobre teatro no sea una tarea profesional o especializada, y que además se ejerza generalmente durante pocas temporadas, no permite en la mayoría de los casos un análisis pormenorizado, argumentado o razonado de las representaciones teatrales. Estamos ante cronistas que no se consideran en muchos casos preparados para ejercer una buena crítica, que renuncian a juzgar las obras bajo la premisa de que ya han sido valoradas por la prensa de otras capitales más importantes. De ahí, y quizás también por el nivel cultural del espectador medio, que se analicen menos los textos y se haga más hincapié en las intervenciones de las compañías o los actores, que el público suele seguir más de cerca, o en el estado del local.

No debe extrañarnos, por tanto, que sólo un $14,28 \%$, de las 2.057 obras recogidas en la cartelera teatral jerezana, 1852-1900, sean enjuiciadas. El grupo de obras que reciben buenas críticas es de 217 , frente a 77 que son criticadas negativamente. Las buenas críticas más extensas se refieren al teatro declamado, la comedia o el drama. A los autores no se les dedican, en general, amplias reseñas, apenas se dan opiniones breves o algunos datos sobre su trayectoria, e incluso en un $85,21 \%$ de las obras representadas ni siquiera se indica su autoría.

Los gacetilleros, conscientes de su doble papel de críticos con determinados géneros, que a su modo de ver pervierten los gustos del público, y formadores u orientadores en el buen gusto, no cejan en sus ataques contra la zarzuela y determinados tipos de dramas, al tiempo que se esfuerzan por enaltecer las obras de los insignes dramaturgos españoles, desde Lope o Calderón, a Echegaray o Tamayo. 
Tras dejar claro que en Jerez se prefiere lo lírico frente a lo dramático, distinguen, grosso modo, dos grupos dentro del género cómico-dramático: por un lado, la legítima literatura dramática, las sublimes creaciones de Calderón y Echegaray; y por otro, los dramas que abundan en escenas de puñal y veneno, los dramas de bandoleros, que embelesan a los sencillos aficionados a las emociones fuertes. Desde las revistas teatrales se argumenta que el público jerezano se inclina por los segundos, esos géneros bastardos, porque no conoce el verdadero arte, por lo que se le ha privado de saborear las excelencias de nuestra literatura dramática.

En esta cuestión, a tenor de la escasa presencia de autores clásicos en la cartelera teatral jerezana de la segunda mitad del siglo XIX, parece que no les faltaba razón. Pero estas mismas circunstancias nos confirman que el gusto de los jerezanos no cambió y que ni empresarios, ni compañías, estaban dispuestos a sacrificar o mermar sus ingresos con el objetivo de subir a las tablas a los autores del Siglo de Oro.

Si bien, como hemos adelantado, los cronistas del espectáculo teatral en Jerez reivindican a los grandes clásicos, en las breves y escasas críticas que escriben sobre su puesta en escena, al igual que ocurre con el resto de autores y salvo alguna excepción, no suelen analizar las obras y se centran en las interpretaciones de los primeros actores.

Lo que son mujeres, de Rojas Zorrilla, fue presentada por una compañía cómico-lírica el día 14 de noviembre de 1852, en el Teatro Principal, y aunque sus componentes, apenas mencionados desde la prensa, eran conocidos en Jerez (El Guadalete, 30-10-1852, n. ${ }^{\circ}$ 61, TEATRO), para El Guadalete la empresa no había acertado al contratar las partes principales (El Guadalete, 20-11-1852, n. ${ }^{\circ}$ 67, TEATRO); parecer refrendado por la ejecución de la obra: «[...] no diremos nada porque nos hace daño acordarnos de ella» (El Guadalete, 16-11-1852, n. ${ }^{\circ}$ 66, Crónica Teatral); mientras se elogia la comedia de Rojas Zorrilla:

[...] agradó por la brillantez, facilidad y armonía de su versificación: en ella no falta naturalidad, y aunque suele degenerar un tanto en gongorina, maneja el autor el idioma con tan singular maestría que encanta y arrebata [...]

El diálogo es rápido y animado [...]

[...] es siempre consecuente con el carácter de sus personajes: los acaba con la misma maestría con que los diseña. El conjunto de la pieza no es digno de alabanza, pero los detalles son magníficos [...] (El Guadalete, 16-11-1852, n. ${ }^{\circ}$ 66, Crónica Teatral). 
De la Compañía dramática, dirigida por los primeros actores D. Victorino Tamayo y Baus y D. José Sánchez Albarrán, durante la temporada 186465, en el Principal, sólo disponemos de una valoración general sobre las funciones ejecutadas:

[...] son muy escogidas y han sido bastante bien desempeñadas, singularmente por los Sres. Tamayo y Sánchez Albarrán, que son dos actores de verdadero mérito dignos de la distinguida reputación que gozan (El Guadalete, 25-4-1865, n. ${ }^{\circ} 3.856$, Crónica Local).

D. Antonio Vico interpreta en el Teatro Eguilaz-Echegaray, por partida doble, a Calderón de la Barca, en El Alcalde de Zalamea, el día 27 de septiembre de 1881, y en La vida es sueño, el 3 de octubre de ese mismo año. De su intervención en la primera nos queda esta concisa impresión:

[...] interpretada con acierto por los apreciables artistas encargados de su ejecución, y muy especialmente por el Sr. Vico, que rayó como siempre a gran altura (El Guadalete, 28-9-1881, n. ${ }^{\circ}$ 7.821, Gacetillas).

Casi una década más tarde, el 16 de febrero de 1891, Vico vuelve a meterse en la piel de Pedro Crespo, ahora en el Teatro Principal. Se repiten los elogios al actor jerezano y se deja constancia de la insuficiente asistencia del público a sus representaciones:

El Lunes inauguró el abono en nuestro Teatro Principal, el ilustre jerezano don Antonio Vico con El Alcalde de Zalamea. Al descorrerse el telón una salva de atronadores aplausos, acogió con entusiasmo á nuestro eminente paisano, que profundamente conmovido daba las gracias al público.

No es ciertamente de sus paisanos de quienes mejores recuerdos guarda el primero de los actores dramáticos de España, pues si bien es cierto que siempre recogió, en las cortas temporadas que entre nosotros ha pasado, gran cosecha de aplausos, no se ha apresurado el público jerezano a llenar las localidades como fuera de desear.

Es una de las obras que mejor interpreta y anteanoche podemos decir que bordó su papel. ¿Qué detalles! [...] (El Guadalete, 18-2-1891, n. . 10.705, Variedades).

La presentación de Carmen Cobeña en el Principal es saludada como un verdadero acontecimiento, que brindaba al público jerezano la oportunidad de ver interpretadas las obras más selectas del teatro clásico y moderno de manera acabada y perfecta (El Guadalete, 14-2-1900, n. ${ }^{\circ} 13.638$, Teatro 
Principal). La Cobeña, señala El Guadalete, sigue el camino trazado por María Guerrero, desenterrando las joyas de nuestro teatro clásico (El Guadalete, 22-11-1897, n. ${ }^{\circ} 12.834$, Revista Teatral). Las expectativas quedaron satisfechas con funciones como la de El vergonzoso en palacio, el día 13 de febrero de 1900, despedida de la compañía:

Carmen Cobeña se conoce que siente a maravilla nuestro gran teatro y que ha estudiado con entusiasmo aquellas damas incomparables de Tirso [...]

Anoche rayó [...] a la altura a donde hayan podido llegar las más famosas y aplaudidas actrices que se han inmortalizado en nuestra escena; no es posible representar más dignidad y gracia, más picaresca expresión y nobleza de sentimientos al par combinados y confundidos en cada escena [...] (El Guadalete, 14-2-1900, n. ${ }^{\circ}$ 13.638, Teatro Principal).

No obstante, montar con propiedad, en consonancia con el carácter que tratan de imitar o con la época en que se desarrolla la acción, a los dramaturgos del Siglo de Oro no estaba al alcance de cualquier compañía. De ahí, que incluso en la representación de la mencionada obra de Tirso, el día 26 de noviembre de 1897, en el Teatro Principal, a cargo de una compañía de prestigio como era la de José Vallés y Carmen Cobeña, apareciera en el primer acto una tropa:

[...] que nadie pudo averiguar si eran soldados y corchetes del siglo XVI o la partida del cura de Santa Cruz [...] produjeron gran risa en el público (El Guadalete, 28-11-1897, n. ${ }^{\circ}$ 12.840, Revista Teatral).

De la breve estancia de la Compañía de María Guerrero y Fernando Díaz de Mendoza en Jerez, del 14 al 18 de septiembre de 1900, las crónicas sólo reseñan, en relación a los clásicos, su magnífica actuación en El desdén con el desdén, de Moreto, el día 16, en el Principal:

María Guerrero caracterizó a la perfección la dama esquiva y desdeñosa [...], tal como la imaginó, sin duda, su inmortal autor.

El admirable diálogo del segundo acto fue dicho por los Sres. de Díaz de Mendoza de modo magistral; no es posible pedir más naturalidad ni acertada expresión en aquella difícil escena, así como en todo el último acto en el que rayó la eminente actriz a grande altura (El Guadalete, 17-9-1900, n. ${ }^{\circ}$ 13.852, Teatro Principal). 


\section{VELADAS LITERARIAS O FUNCIONES CONMEMORATIVAS Y OTROS ASPECTOS EN TORNO A LA PRESENCIA DE LOS AUTORES CLÁSICOS EN LA VIDA ESCÉNICA JEREZANA}

Entre las veladas literarias, Agustín Muñoz y Gómez hace referencia a la primera que tuvo lugar en Jerez el 23 de abril de 1878 en honor de Cervantes (Muñoz y Gómez, 1891) y desde El Guadalete se comentan las celebradas el 23 de abril de 1880 y el 25 de mayo de 1881, cuyos protagonistas respectivos fueron el autor del Quijote y Calderón de la Barca.

La velada artístico-literaria de abril del ochenta se llevó a cabo en el Teatro Eguilaz. Consistió en la lectura de una serie de trabajos realizados como homenaje a Cervantes y estuvo amenizada con la actuación de la orquesta de la Academia Filarmónica (El Guadalete, 25-4-1880, n. ${ }^{\circ}$ 7.379, Gacetillas).

El segundo centenario de la muerte de Calderón se conmemoró en ese mismo teatro con la actuación de la Compañía de zarzuela de Isidoro Pastor, que puso en escena Los comediantes de antaño y El loco de la guardilla. La función estaba dedicada a los Sres. Socios de los Casinos Nacional y Jerezano, y se leyeron en los intermedios poemas dedicados a Calderón:

El retrato del eminente poeta [...] presidía el acto y en el teatro había grandes tarjetones con los títulos de sus más escogidas obras (El Guadalete, 28-51881, n. ${ }^{\circ} 7.717$, Gacetillas).

Calderón también estuvo presente en las reformas acometidas por Francisco Aliaño, en el Teatro Echegaray, durante la temporada de 1882-83. Su retrato, junto al de Eguilaz y Echegaray, formaba parte de la decoración interior ejecutada por el citado pintor escenógrafo (El Guadalete, 10-5-1883, n. ${ }^{\circ} 8.322$, Variedades).

Otro autor, no representado en Jerez en este período, Juan Ruiz de Alarcón (1581-1639), prestó su nombre a la asociación de aficionados al arte dramático más activa de la ciudad. La Asociación Artística y Círculo Recreativo Ruiz de Alarcón, inauguró su elegante y bonito teatro el día 22 de diciembre de 1878, con una función en la que como parte del programa se leyeron al principio unas décimas en honor al insigne poeta novohispano ( $E l$ Guadalete, 24-12-1878, n. ${ }^{\circ}$ 6.965, Gacetillas). 


\section{CONCLUSIONES}

Los autores que presentan sus obras en Jerez en la segunda mitad del siglo XIX ascienden a 487. Seis de ellos se enmarcan en el Siglo de Oro, $1,23 \%$, y dos en el siglo XVIII, $0,41 \%$. En la relación de autores dramáticos según las representaciones que tienen lugar de sus obras, 42 superan las 100 representaciones. Entre 10 y 100 representaciones se dan de 147 autores, es el caso de Ramón de la Cruz, con 22. Entre 5 y 9,67 autores y aquí encontramos a Calderón con 8 y a Rojas Zorrilla con 8. Entre 2 y 4, 128 autores, como Moreto con 4, Tirso y Lope de Vega con 3 y Moratín con 2. 103 autores fueron puestos en escena una vez, entre ellos Guillén de Castro. Ramón de la Cruz ocupa en la lista de autores, según las representaciones, el número 113 y Calderón el 201.

En cuanto al número de autores, según las obras representadas, 7 estrenaron en Jerez 30 o más obras; 11 presentaron entre 20 y 29 obras; 27 presentaron entre 10 y 19 obras; entre 5 y 9 obras encontramos 40 autores; con 4 obras 29 autores, es el caso de Calderón; con 3, 36, Ramón de la Cruz entre ellos; con 2, 73, como Moratín, Tirso, Rojas Zorrilla y Moreto; y con 1, 264, con los ejemplos de Lope de Vega y Guillén de Castro. Calderón ocupa en la relación de autores, según las obras representadas, el número 110 y Ramón de la Cruz el 122.

Esta escasa presencia de los autores clásicos en los teatros de la ciudad queda ratificada por el hecho de que de un total de 6.280 funciones, 27 corresponden al teatro clásico del Siglo de Oro español, es decir un 0,42\%, y 24 al siglo XVIII, un 0,38\%. Conclusiones similares nos aporta el número de obras, ya que de las 2.057 que se pusieron en Jerez, entre 1852 y 1900, las 11 cuyos autores corresponden al Siglo de Oro, suponen un 0,48\% del total, mientras que las 5 de autores del siglo XVIII se quedan en el 0,24\%.

De las 312 compañías que recalan en Jerez, entre 1852 y 1900, sólo 21 representaron autores del Siglo de Oro, un 6,73\%; y 18, un 5,76\%, a dramaturgos del siglo XVIII. Además, las obras clásicas ocupan un lugar simbólico en los repertorios de las compañías. Así, por citar algunas de las más representativas, la de Tamayo-Albarrán, durante la temporada 1864-65, dio 60 funciones y sólo en dos de ellas se pusieron en escena obras de los clásicos. La compañía dirigida por Francisco de Paula Gómez, en la temporada 61-62, alcanzó 51 funciones y sólo en una se interpretó a Rojas Zorrilla. Cobeña y Vallés, ofrecieron 23 funciones en la temporada 97-98, tres de ellas con obras clásicas. 
Todos estos antecedentes inciden en la escasa presencia del teatro del Siglo de Oro y del siglo XVIII en la cartelera teatral jerezana de 1852-1900. Sin embargo, al mismo tiempo, comprobamos que las escuetas valoraciones de que disponemos sobre estos autores, sus obras y sus puestas en escena, son muy positivas. Se los considera lo mejor del teatro español, junto a algunos dramaturgos del siglo XIX. De ahí, que nos preguntemos a qué se debe esta contradicción. Para los cronistas de la época el público jerezano no desprecia el teatro clásico, sino que lo desconoce, ha visto poco de este gran teatro, se les ha privado de admirarlo con la frecuencia que sería de desear. Por ello, se muestran partidarios de despertar el buen gusto del público, de aficionarlo a este espectáculo civilizador, ofreciéndole temporadas de buenas obras en su teatro y haciendo esfuerzos desde la prensa por enaltecer el género dramático.

No parece, sin embargo, que los aficionados jerezanos respondieran a esta llamada, pues se inclinan por el teatro musical y nos consta el bajo nivel de asistencia a las representaciones de obras clásicas protagonizadas por grandes actores o la corta permanencia en Jerez de compañías dramáticas de prestigio que incluían autores clásicos en su repertorio. Tampoco los empresarios o los directores de las compañías, salvo algunas excepciones, toman nota de estas recomendaciones y, en general, para que una compañía pudiera subsistir una buena temporada en la ciudad debía ofrecer variedad en el espectáculo y, si era dramática, sazonarla con lo cómico, lo lírico o lo coreográfico. Si a ello añadimos la dificultad que suponía montar con propiedad una obra clásica, tanto por la formación que exigía a los actores, como por la inversión en escenografía o vestuario, obtenemos, en definitiva, conclusiones similares a las verificadas en otros estudios con respecto a la poca fortuna del teatro áureo en la cartelera teatral de la segunda mitad del siglo XIX y en las razones que lo motivaron.

Irene Aragón, en su aproximación al estado de la cuestión sobre la puesta en escena del teatro del Siglo de Oro en varias poblaciones españolas durante el siglo XIX, compiló dichas causas (Aragón González, 2006: 18), y sobre el número de obras clásicas llevadas a los escenarios, la comparación entre Jerez y las investigaciones realizadas en tres de estas ciudades, para períodos similares, evidencian una vez más su escasa presencia en el desarrollo del espectáculo teatral decimonónico en diversas zonas de la geografía nacional:

- Jerez, 1852-1900: 2.057 obras representadas; 11 obras clásicas, $0,48 \%$ del total. 
- Badajoz,1860-1900: 1.370, 2, 0,14\%

- Las Palmas, 1853-1900: 855, 5, 0,58\%

- León, 1843-1900: 770, 1, 0,12\%

Si además, nos fijamos en los autores, los títulos y las compañías que los representaron, comprobamos que todas las obras escenificadas en estas tres ciudades también llegaron a Jerez, lo cual nos indica que el repertorio representado se circunscribe a varios títulos emblemáticos, con un solo autor, Calderón de la Barca, presente en las cuatro carteleras cotejadas.

Badajoz:

- El Alcalde de Zalamea, Calderón. Cía. de Antonio Vico, 6-08-1892.

- La niña boba, Lope. Cía. cómico-lírica de Luisa Calderón, 21-081897.

(Suárez Muñoz y Suárez Ramírez, 2006: 92-94).

León:

- La vida es sueño, Calderón. Compañías de aficionados, 20-05-1881 y 3-04-1893.

Cía. de Antonio Vico, 15-06-1882.

(Fernández García, 2006: 40).

Las Palmas de Gran Canaria:

- La niña boba, Lope. Cía. dramática de Matilde Martínez, 30-121859.

Cía. dramática de María Guerrero, 13-11-1899.

- Casa con dos puertas mala es de guardar, Calderón. Cía. de V. Tamayo, 19-10-1872.

- García del Castañar, Rojas Zorrilla. Cía. Victorino Tamayo, 29-101872.

- La vida es sueño, Calderón. Cía. dramática de Manuel Espejo, 24-041895.

- El desdén con el desdén, Agustín Moreto. Cía. de María Guerrero, 20-11-1899.

(López Cabrera, 2006: 74-79). 
La puesta en escena de los autores del Siglo de Oro se restringe aún más si advertimos que las compañías que los acercaron al público de estas localidades coinciden en torno a grandes actores o actrices como Vico, Tamayo o María Guerrero, que, a su vez, contribuyen a que las representaciones de obras clásicas se incrementen durante las últimas décadas del siglo.

Por lo que atañe al teatro español del siglo XVIII, se presentan dos obras de Moratín, un autor cuya vida se adentra de lleno en el siglo XIX y, sobre todo, está presente con los populares sainetes de Ramón de la Cruz, que no requieren mucho aparato escénico, completan, aligeran y aportan variedad a las funciones. Salvo esta última excepción, podemos decir que se trata de un teatro prácticamente ausente de los escenarios jerezanos a lo largo de la segunda mitad del siglo XIX.

\section{REFERENCIAS BIBLIOGRÁFICAS}

ÁLVAREZ HORTIGOSA, F. (2009). Historia del teatro en Jerez de la Frontera durante la segunda mitad del siglo XIX. Tesis doctoral defendida en la Universidad de Cádiz en febrero de 2009. Inédita [De nuestra tesis obtenemos todos los datos aportados sobre el espectáculo teatral en Jerez].

ARAGÓN GONZÁLEZ, I. (2006). «Estado de la cuestión: Puestas en escena de nuestro teatro áureo en algunas ciudades españolas durante los siglos XIX y XX. Presentación». Signa. Revista de la Asociación Española de Semiótica 15, 11-18 (también en http://cervantesvirtual.com/ hemeroteca/signa).

CENTRO DE INVESTIGACIÓN DE SEMIÓTICA LITERARIA, TEATRAL Y NUEVAS TECNOLOGÍAS (UNED). «Estudios sobre teatro»: http://www.uned.es/centro-investigacion-SELITEN@T/estudios sobre_teatro.html.

FERNÁNDEZ GARCÍA, E. (2006). «León 1843-1900». Signa. Revista de la Asociación Española de Semiótica 15, 39-42 (también en http://cervantes virtual.com/hemeroteca/signa).

LÓPEZ CABRERA, M. ${ }^{\mathrm{a}}$ del Mar (2006). «Las Palmas de Gran Canaria (1853-1900)». Signa. Revista de la Asociación Española de Semiótica 15, 73-83 (también en http://cervantesvirtual.com/hemeroteca/signa). 
MUÑOZ Y GÓMEZ, A. (1891). Efemérides de Historia Jerezanas, general y artístico musical. Tomo II, año 1891, día 23 de abril. Jerez de la Frontera: Imp. «El Guadalete».

SUÁREZ MUÑOZ, Á. y S. SUÁREZ RAMÍREZ (2006). «Badajoz (18601900)». Signa. Revista de la Asociación Española de Semiótica 15, 85-96 (también en http://cervantesvirtual.com/hemeroteca/signa). 